\section{Powder and Crack Cocaine Use as a Determinant of Sexually Transmitted Infections (STIs) Occurrence among US Juvenile Offenders}

\section{Abstract}

Background: The prevention of sexually transmitted infections (STIs) among adolescents is a major concern across the globe, in particular in the United States (U.S.), and A common indicator of risk in documented in the literature for STIs is substance use.

Method: Participants were 2260 juvenile offenders in the state of Georgia. Significance tests were conducted using univariate logistic regressions to examine the independent associations of participant's self-reported crack and powder cocaine use and dichotomized HIV risk behaviour correlates and history of having a prior STI before the most recent incarceration.

Results: With respect to specific STI occurrence, participants who reported powder cocaine use were more likely to have reported having been told they had genital warts (OR=1.33, 95\% Cl=0.58-3.02), Chlamydia (OR=1.27, 95\% Cl=0.83-1.95), Syphilis (OR=1.33, 95\% Cl=0.58-3.02) and Trich (OR=1.39, 95\% Cl=0.82-2.38). Participants who reported past Crack use were three times more likely to having been told they had Syphilis prior ( $\mathrm{OR}=3.39,95 \% \mathrm{Cl}=0.49-23.41$ ). Participants who reported using crack were three and two time to indicate that had been informed prior that they had Herpes $(\mathrm{OR}=3.04,95 \% \mathrm{Cl}=0.44-2.1 .16)$ and Trich $(\mathrm{OR}=2.32$, $95 \% \mathrm{Cl}=0.73-7.41$ ) accordingly.

Conclusion: Even across racial/ethnic groups, gender, and geographic locations, several determinants of adolescents' sexual risk taking were identified. Of importance, is the need for STI risk reduction interventions to consider using more measures of overall reproductive health, especially for female juvenile offenders.

Keywords: Cocaine; Sexually transmitted infections (STIs); Adolescents; HIV risk
Torrance Stephens ${ }^{1}$, L Cecil Powell², Rhonda Conerly Holliday²

\section{Clark Atlanta University: Department of Psychology; School of Education, Atlanta, Georgia, USA \\ 2 Preventive Medicine, Morehouse School of Medicine, USA}

Corresponding author:

Torrance Stephens

\section{$\risingdotseq$ tstephensphd@gmail.com}

Department of Psychology, School of Education, Clark Atlanta University, Atlanta, Georgia, USA

Tel: 4048808236

Citation: Stephens T, Powell LC, Holliday RC. Powder and Crack Cocaine Use as a Determinant of Sexually Transmitted Infections (STIS) Occurrence among US Juvenile Offenders. J Drug Abuse. 2015, $1: 1$.

Received: October 02, 2015, Accepted: November 18, 2015, Published: November 25, 2015

\section{Introduction}

The prevention of sexually transmitted infections (STIs) among adolescents is a major concern across the globe, in particular in the United States [1-6]. Namely because STIs are a significant source of morbidity for adolescents and young adults [4, 5]. A common indicator of risk documented in the literature for STIs is substance use [7-12]. Consequently, substance use reduction and abrogation are considered essential and primary in HIV/STI risk reduction health intervention efforts that target adolescents and young adults [13-16].
Among adults, crack and cocaine use has been shown to be associated with co-occurring psychiatric disorders, unprotected sex and other drug use, as well as psychiatric disorders among adolescents [17]. Likewise, with respect to adult incarcerated populations, it has been demonstrated to be a predictor of lack of condom use and having unprotected sex [18]. In comparison, among adolescents, in particular juvenile offenders, cocaine use has been shown to be associated with co-occurring psychiatric disorders in some samples $[19,20]$.

Epidemiological research with adolescents has consistently 
shown that those who engage in delinquent activities are particularly vulnerable for the STIs like HIV [21]. Adolescent juvenile offenders are at risk for acquiring sexually transmitted infections (STIs) and exhibit higher rates of risk behaviors, inclusive of drug and alcohol use during sex than adolescents without a history of incarceration [22, 23]. In particular, this population has been shown to start sexual activity earlier [24], use condoms less often [25], and have higher rates of STIs [21, 23, 24, 26, 27]. This is problematic given it has been reported that 70 percent of incarcerated adolescents regularly use one or more substances which consequently increases the likelihood of having sex with multiple partners almost 12 times more than non-users [28].

When cocaine is documented to be used by adolescents, emerging evidence strongly suggests that its uses impacts practices inclusive of condom use by adolescents, having multiple partners, injection drug use, and poly substance use prior to being booked [29-32]. All of which are factors that may contribute to tendencies for sexual risk taking. Moreover, the consequence of crack use in concert with sexual risk taking has been associated with a multitude of problem behaviors ranging from psychiatric issues to problem violent behavior [33-38].

Although a corpus of investigations have summarized empirical findings relevant to the correlates of adolescents' cocaine use regarding STI risk behaviors, the information presented rarely evaluates distinctions between powder and crack cocaine use by adolescent juvenile offenders. Moreover, these efforts lacks a relational perspective since many target specific gender or racial/ethnic groups, potentially limiting the generalizability of the findings for the design of STI risk reduction interventions for adolescent incarcerated populations that may have substance use issues. Last, associations between adolescents offender self-reported sexual behavior and cocaine use typically does not examine perceptions of expectations pertaining reference to specific STIs. Thus, the purpose of this study was to determine the association of self-reported crack and powder cocaine use with past occurrence of a STI use among a large sample of at-risk adolescent juvenile offenders in Georgia, USA.

\section{Method}

\section{Participants}

Participants were 2260 juvenile offenders housed at selected Youth Development Campuses (YDCs) in the state of Georgia. The YDCs were gender specific and operated under the auspices of the State Department of Juvenile Justice. For this study, females were over sampled. Adolescents sentenced to theses YDCs during the study period were approached by health educators within the first three days of being admitted into the facilities, presented with an overview of the study and asked to participate.

Prior to study implementation, approval was obtained from the university and the Department of Juvenile Justice Institutional Review Boards. In addition, participants were informed that being a part of this study was voluntary and that all information would be private and unavailable to YDC staff. Adolescents who agreed to take part in the study signed an assent formed that gave members of the research team permission to contact their parents and/or legal guardian for their approval for participation.
Based on IRB requirements, assent must be obtained from the children who participate in research unless they are not capable of understanding what is being asked of them. If assent is requested of and not granted by a child, the child's refusal to participate in the research was binding.

In total, 4031 adolescents were approached for the study of which 2060 were included in this analysis. The questionnaire was interviewer administered and was administered within the first month after admittance in the YDCs by trained staff recruited from the communities located around the YDCs.

Significance tests were conducted using univariate logistic regressions to examine the independent associations of participant's self-reported crack and powder cocaine use and dichotomized HIV risk behavior correlates and history of having a prior STI before the most recent incarceration. Adjusted odds ratios (ORs) with $95 \%$ confidence intervals (Cls) are presented. Univariate regression analysis was selected because the least squares regression curve will minimizes the sum of squared differences between the estimated and the actual $y$ values for given $x$ values as well because of the given assumption of normality. This means that the sum of squares and partial derivatives of each parameter estimated in each equation are defined and equated to zero.

\section{Measures}

\section{Demographics}

Participants reported their age, race, and years of formal education, year's incarcerated and prior arrest.

\section{Powder and crack cocaine use}

These items were measured using two separate items from the drug use measures included in the survey instrument measured on scale from 0 to 5 ( $0=$ never, $1=1$ to 2 days, 2=3 to 5 days, $3=6$ to 9 days, $4=10$ to 19 days and $5=20$ to 31 days). These response categories were recoded to compute a dichotomous variable of $1=$ never and 2=prior uses. Specifically, items asked during the last month before entering a detention center or YDC, how often have you used any of the following on your own that is, without a doctor telling you to take them. Participants with missing data were not included in the analysis.

\section{STI symptomology}

Participants responded to eight dichotomous items covering selected symptomology of possible STI infection. All items were prefaced with, "In the last year, have you ever had any of the following happen to you." Sample items from the instrument were "sore bumps of blisters near your sex organs or mouth", for males, "a drip or drainage from the penis," and for females, "burning or itching around the vagina."

\section{STI history}

This variable was assessed with seven items specific to having been informed prior their current detention, if they had ever been informed that they had a STI by a doctor or a nurse. Dichotomous response options (yes or no) were collected and recorded for the 
following STIs: Genital Warts, Chlamydia, Syphilis, Gonorrhea, Herpes, Trich and Crabs (pubic Lice).

\section{Results}

Sample respondents were mainly female $(58.8 \%, n=1339)$ with African American and whites comprising $56.8(n=1293)$ and $36.9(n=840)$ percent of respondents accordingly, of which 55.5 $(n=1263)$ percent reported being locked up prior to the current incarceration. Overall, participants ranged in age from 11-18 years (mean=15.2, SD 1.16), with males being older than females. The mean age for participants age of first using marijuana and alcohol was $12.7(\mathrm{SD}=1.9)$ and $12.8(\mathrm{SD}=2.25)$ years accordingly. Chi Square analysis did yield significant difference among sample participants based on presence self-reported consideration of suicide with respect to gender, ethnicity and being locked up prior to the current incarceration period.

\section{Powder cocaine use}

Bivariate associations between the assessed powder cocaine use correlates and self-reported STI symptomology and occurrence (e.g., yes versus never) as well as corresponding prevalence ratios and their 95\% confidence intervals are presented in Table 1. Table 2 also serves a descriptive purpose by showing the proportions of those who reported having ever used powder cocaine previously, and those that did not with respect to their agreement or disagreement with selected correlates. Of note, eight of the fourteen correlates indicated that prior arrest was a potential risk factor. Associations were based on remarkably similar proportions (that is, the difference between groups was extremely small).

Juveniles who reported having used powder cocaine previously were more likely to report that they had sore bumps of blisters near their sex organs before $(\mathrm{OR}=1.69,95 \% \mathrm{Cl}=1.07-2.69)$, having experienced burning or pain when urinating (OR=1.96, 95\% $\mathrm{Cl}=1.42-2.71$ ), feeling that they needed to urinate frequently (OR=1.69, 95\% $\mathrm{Cl}=1.27-2.24)$, having a drip or drainage from the penis $(\mathrm{OR}=1.76,95 \% \mathrm{Cl}=0.72-4.32)$, having vaginal discharge or odor from their vagina $(\mathrm{OR}=1.54,95 \% \mathrm{Cl}=1.83-2.19)$, pain in the lower pelvis or deep in the vagina during sex $(O R=2.01$, 95\% $\mathrm{Cl}=1.23-3.36)$ and experiencing burning or itching around the vagina $(\mathrm{OR}=1.72,95 \% \mathrm{Cl}=1.09-2.71)$. In addition, female respondents reported experiencing bleeding from the vagina at time other when they were on their periods (OR=2.51, 95\% $\mathrm{Cl}=1.61-3.88)$ if they have ever used powder cocaine. Significant differences was observed between powder cocaine users and non-users for having bumps of blisters near their sex organ, experiencing burning or pain when they urinated, feeling the need to urinate frequently, having a vaginal discharge or odor from the vagina, pain in the lower pelvis and bleeding from the vagina at times other than their period (all p's<0.029).

With respect to specific STI occurrence, participants were more likely to have reported having been told they had genital warts (OR=1.33, 95\% Cl=0.58-3.02), Chlamydia (OR=1.27, 95\% Cl=0.831.95), Syphilis (OR=1.33, 95\% $\mathrm{Cl}=0.58-3.02)$ and Trich (OR=1.39, $95 \% \mathrm{Cl}=0.82-2.38)$. However, study participants were less likely to have been told by a nurse that they had Crabs or pubic lice, Herpes
Table 1 Demographic Profile of Study Participants Based on Gender (missing values not included).

\begin{tabular}{|c|c|c|c|}
\hline Variable & Male \% (n) & Female \% (n) & p \\
\hline & $n=939$ & $n=1338$ & \\
\hline Race & & & 0.062 \\
\hline White & $37.7(354)$ & $36.3(486)$ & \\
\hline Black & $56.3(529)$ & $57.1(764)$ & \\
\hline Hispanic & $2.6(24)$ & $1.9(25)$ & \\
\hline Asian & $1.1(10)$ & $0.4(6)$ & \\
\hline Native American & $0.3(3)$ & $0.4(6)$ & \\
\hline Other & 2.0 (19) & $3.8(51)$ & \\
\hline Highest Grade of School Finished & & & 0.001 \\
\hline $4^{\text {th }}$ & $0.0(0)$ & $0.2(3)$ & \\
\hline $5^{\text {th }}$ & $0.0(0)$ & $2.4(32)$ & \\
\hline $6^{\text {th }}$ & $1.4(13)$ & $6.9(92)$ & \\
\hline $7^{\text {th }}$ & $15.9(94)$ & $7.3(245)$ & \\
\hline $8^{\text {th }}$ & $34.5(323)$ & $31.6(420)$ & \\
\hline $9^{\text {th }}$ & $33.2(310)$ & $24.5(325)$ & \\
\hline $10^{\text {th }}$ & $15.9(154)$ & 13.5 (179) & \\
\hline $11^{\text {th }}$ & $4.9(38)$ & $2.2(29)$ & \\
\hline $12^{\text {th }}$ & $0.3(3)$ & $0.2(3)$ & \\
\hline Locked Up Before This Time & & & 0.016 \\
\hline Yes & $58.5(549)$ & $53.4(714)$ & \\
\hline No & 38.5 (389) & $46.6(622)$ & \\
\hline Ever Used Powder Cocaine & & & 0.323 \\
\hline Yes & $11.4(106)$ & $10.1(135)$ & \\
\hline No & $88.6(822)$ & $89.9(1198)$ & \\
\hline Ever Used Crack Cocaine & & & 0.158 \\
\hline Yes & $1.2(11)$ & $2.0(26)$ & \\
\hline No & 98.8 (917) & 98.0 (1307) & \\
\hline
\end{tabular}

or Gonorrhea. No significance was observed with respect to having been told by a nurse that they had any of the aforementioned by a nurse. These findings are outlined in Table 3.

\section{Crack cocaine use}

Study participants who reported having used crack cocaine previously were more likely to report having experienced burning or pain when urinating $(\mathrm{OR}=1.41,95 \% \mathrm{Cl}=0.50-3.91)$, feeling that they needed to urinate frequently $(\mathrm{OR}=1.96,95 \% \mathrm{Cl}=0.93-4.13)$, having a drip or drainage from the penis $(\mathrm{OR}=4.46,95 \% \mathrm{Cl}=0.59$ $33.19)$, having vaginal discharge or odor from their vagina $(\mathrm{OR}=1.22$, $95 \% \mathrm{Cl}=0.49-3.01$ ) and pain in the lower pelvis or deep in their vagina (OR=2.09, 95\% Cl=0.64-6.83) Female respondents that said they used crack cocaine also were two times more likely to have reported experiencing bleeding from the vagina at time other when they were on their periods (OR=2.12, 95\% $\mathrm{Cl}=0.65-6.91)$.

With respect to specific STI occurrence, participants were more likely to have reported having been told they had genital warts (OR=1.73, 95\% Cl=0.24-12.27), Chlamydia (OR=1.69, 95\% $\mathrm{Cl}=0.61-4.71)$ and were three times more likely to having been told they had Syphilis prior ( $\mathrm{OR}=3.39,95 \% \mathrm{Cl}=0.49-23.41$ ). Juvenile offenders who reported using crack also were three and two time to indicate that had been informed prior that they had Herpes (OR=3.04, 95\% $\mathrm{Cl}=0.44-2.1 .16)$ and Trich (OR=2.32, 95\% $\mathrm{Cl}=0.73-7.41)$ accordingly. 
Table 2 Bivariate Logistic Regression of Self-Reported Powder Cocaine Use and STI Symptomology and STI History.

\begin{tabular}{|c|c|c|c|c|}
\hline Factors & Never $(n=2020)(\%)$ & Used $(n=241)(\%)$ & OR & $95 \% \mathrm{Cl}$ \\
\hline \multicolumn{5}{|c|}{ In the past year, have you ever had any of the following happen to you } \\
\hline $\begin{array}{l}\text { Sore bumps of blisters near your } \\
\text { Sex organs or mouth }\end{array}$ & & & 0.54 & $0.31-0.94$ \\
\hline Yes & 3.7 & 6.6 & 1.69 & $1.07-2.69$ \\
\hline No & 96.3 & 93.4 & 0.91 & $0.83-1.01$ \\
\hline Burning or pain when you urinate & & & 0.45 & $0.31-0.67$ \\
\hline Yes & 7.2 & 14.5 & 1.96 & $1.42-2.71$ \\
\hline No & 92.8 & 85.5 & 0.89 & $0.82-0.96$ \\
\hline Feeling that you need to urinate frequently & & & 0.54 & $0.39-0.76$ \\
\hline Yes & 13.1 & 21.7 & 1.69 & $1.27-2.24$ \\
\hline No & 86.9 & 78.3 & 0.92 & $0.87-0.97$ \\
\hline A drip or drainage from your penis (males) & & & 0.51 & $0.16-1.56$ \\
\hline Yes & 2.0 & 3.8 & 1.76 & $0.72-4.32$ \\
\hline No & 98.0 & 96.2 & 0.90 & $0.72-1.12$ \\
\hline $\begin{array}{c}\text { Vaginal discharge or odour from your } \\
\text { vagina (females) }\end{array}$ & & & 0.61 & $0.41-0.92$ \\
\hline Yes & 18.8 & 27.4 & 1.54 & $1.08-2.19$ \\
\hline No & 81.2 & 72.6 & 0.94 & $0.89-0.99$ \\
\hline $\begin{array}{l}\text { Pain from your lower pelvis or deep in } \\
\text { The vagina during sex (females) }\end{array}$ & & & 0.44 & $0.24-0.80$ \\
\hline Yes & 5.2 & 1.1 & 2.01 & $1.23-3.26$ \\
\hline No & 94.8 & 88.9 & 0.89 & $0.79-0.99$ \\
\hline $\begin{array}{l}\text { Burning or itching around the vagina } \\
\text { (female) }\end{array}$ & & & 0.53 & $0.31-0.92$ \\
\hline Yes & 7.6 & 13.3 & 1.72 & $1.09-2.71$ \\
\hline No & 92.4 & 86.7 & 0.92 & $0.84-1.00$ \\
\hline $\begin{array}{l}\text { Bleeding from the vagina at times other } \\
\text { Than your period (female) }\end{array}$ & & & 0.33 & $0.19-0.59$ \\
\hline Yes & 4.9 & 13.3 & 2.51 & $1.61-3.88$ \\
\hline No & 95.1 & 86.7 & 0.84 & $0.74-0.96$ \\
\hline Genital Warts & & & 0.72 & $0.27-1.87$ \\
\hline Yes & 1.5 & 2.1 & 1.33 & $0.58-3.02$ \\
\hline No & 98.5 & 97.9 & 0.96 & $0.83-1.10$ \\
\hline Chlamydia & & & 0.75 & $0.46-1.24$ \\
\hline Yes & 6.5 & 8.4 & 1.27 & $0.83-1.95$ \\
\hline No & 93.5 & 91.6 & 0.52 & $0.96-1.03$ \\
\hline Syphillis & & & 0.96 & $0.22-4.23$ \\
\hline Yes & 0.8 & 0.8 & 1.03 & $0.84-1.17$ \\
\hline No & 99.2 & 99.2 & .52 & $0.27-3.82$ \\
\hline Gonorrhea & & & 1.19 & $0.57-2.18$ \\
\hline Yes & 4.7 & 4.2 & 0.90 & $0.49-1.65$ \\
\hline No & 95.3 & 95.8 & 1.01 & $0.94-1.08$ \\
\hline
\end{tabular}

\section{Discussion}

This study provided important data documenting the extent to which power and/or crack cocaine use place adolescents juvenile offenders at risk of sexually transmitted infections (STIs), including HIV. The findings suggest there are a few distinctions between sexually risk taking and the occurrence in STIs among this sample. This is because substance use is a problem behavior that not only increases adolescents likelihood of being incarcerated via use and distribution, but it is also associated with other problem behaviors including but not limited to weapon carrying, fighting and poly-substance use [39]. Moreover, the observation that females who reported using powder cocaine in the sample were two times more likely to report burning or itching around the vagina and two and a half times more likely to report bleeding from the vagina at times other than their period may indicate pertaining to reproductive health other than having been told they may or may not have had an STI. Since we did not examine data regarding to prior history of abortion, it is difficult to gauge the actual meaning of these findings.

Although participants were in most case more likely to have been told they had an STI, the rates were not alarmingly as high as we would have anticipated. In addition, it was observable that in 
Table 3 Bivariate Logistic Regression of Self-Reported Crack Cocaine Use and STI Symptomology and STI History.

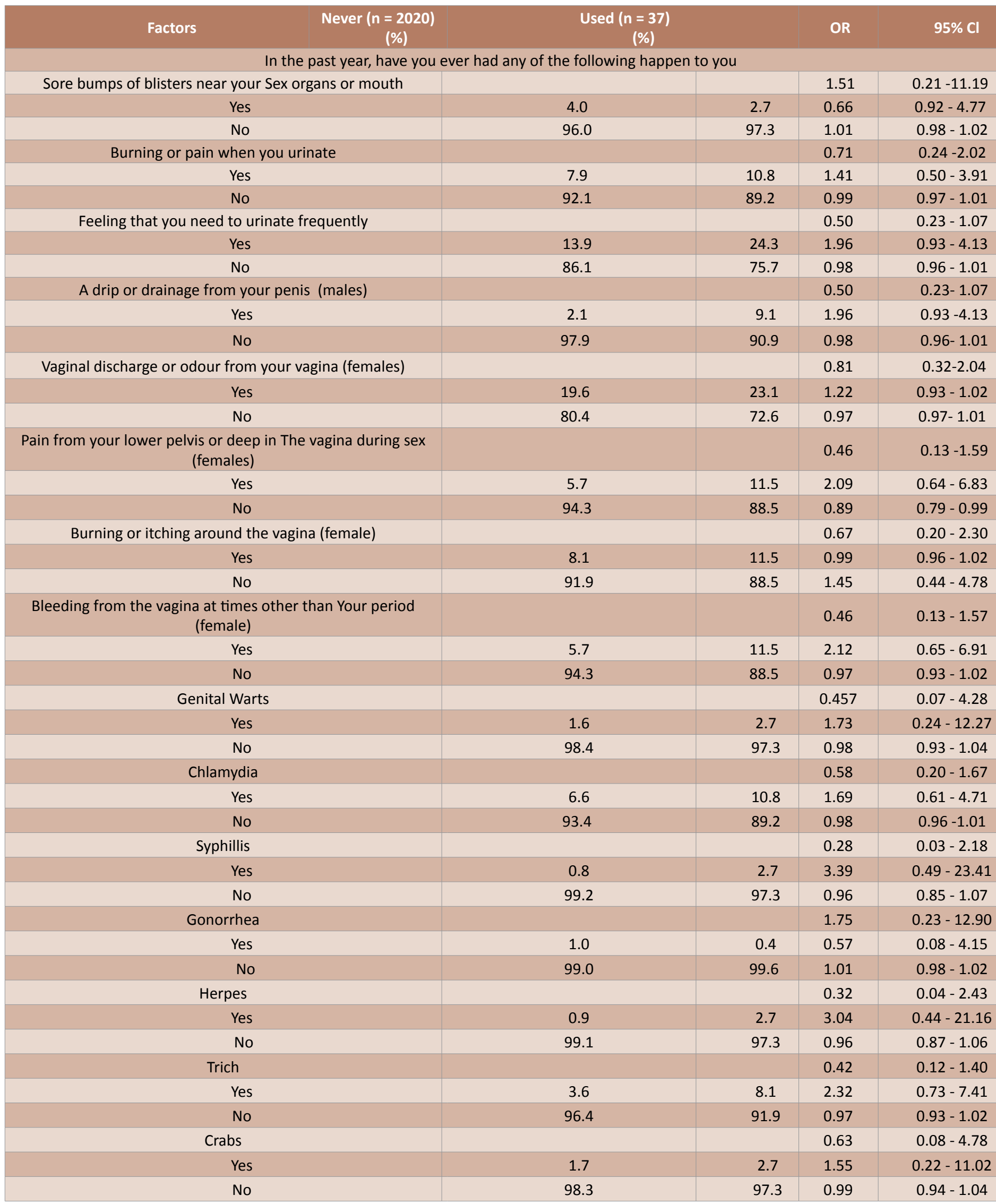


terms of preference powder cocaine use was reported more than crack use which may suggest the popularity of the latter may be on the decline with this population.

It is positive to note that just small proportion of study respondents reported having used powder $(10.7 \%)$ or crack (1.6\%), despite potentially being subjected to substantial peer pressure and given that other studies have reported 23 percent had used cocaine or crack in the month before arrest [39]. Based on this, it is reasonable to assert that programs conducted in adolescent detention facilities could be designed specifically to help this population avoid engaging in health-risk behaviors associated with increasing the likelihood of contracting STIs such as HIV.

Data herein also have implications for community-based sexual risk-reduction programs for adolescents. For example, smallgroup workshops are an excellent opportunity to empower juvenile offenders and assist in engendering self-protective risk reducing practices, as well as aid in addressing both gender and cultural norm-setting that may assist in curbing the spread of STIS among juvenile detainees.

These can focus of skill development ranging for condom use and condom use self-efficacy as well as effective condom negotiation skills. Thus researchers and health education specialist can take advantage of that unlike typical adolescent populations, juvenile offenders offer an environment that is readily accessible for STI risk reduction interventions that target future risk practices as well as promote self-efficacious behaviors. Such interventions would need to target STIs, substance use and pregnancy among this population, in particular for females, given the elevated rate of pregnancy and spread of heterosexual sexually transmitted infections among adolescents [23, 26, 30, 40, 41].

\section{Limitations}

Findings are limited by the validity of the self-reported data; however, the design included multiple strategies to enhance validity. Mainly because the reliance on a methodology that involves the self-reported outcome measures (i.e., substance use) may proffer concerns regarding findings and results. Although a multitude of studies have supported validity and reliability of selfreport sexual behavior $[42,43]$ none examined juvenile detainees whom were predominantly African Americans. Other limitations pertain to how much of extent attrition, despite statistical assurances that attrition bias did not occur and issues regarding our sample size. Another factor is the very small number of participants who reported using crack cocaine, although we surveyed more than two thousand juveniles.

We also acknowledge that observed associations are crosssectional; thus, causality cannot be determined. Clearly, prospective analyses and interventions that target relevant condom use attitudes are needed to corroborate these findings. Also, adolescents with a history of unprotected sex were enrolled, so these findings may not generalize to less-at-risk youth. Nevertheless, the multiple recruitment methods employed at each site resulted in a convenience sample of ethnically and racially diverse sexually active adolescents in several locations in the U.S. These conditions allow for conclusions that are not limited to one city or ethnic/racial group.

Another major limitation of our study pertains to sample size, specifically the small sample size of the self-reported crack cocaine use group in contrast with non-users. Research notes that many behavioral studies may be influenced by the presence of confounding variables [44]. Consequently, larger sample sizes are preferred since confounding variables must be controlled for in the analysis. Thus a more complex statistical model may have been required, albeit our goal was compare the ranges of users versus non users. Moreover, the value of the statistical significance depends on the standard error of the estimator and the power of the study. Therefore, given the smaller male sample size, our level of power is severely decreased, thus our findings may reflect such in the resulting risk ratios and 95\% Cis with respect to crack cocaine use [45]. This has been reported to occur because Logistic regression overestimates odds ratios in studies with small to moderate samples size by inducing systematic bias in a direction away from the null hypothesis away from null (odds ratios shift away from one) [46].

\section{Conclusion}

We believe our findings add to our current understanding of drug use and outcomes associated with increased risk of spreading STIs. In particular based on the observation that little is available in the literature regarding cocaine use (crack or powder), its association with adolescent offenders sexual risk behaviors and practices. What is known is that one investigation did not see cocaine use during the last 3 months as a significant predictor of the number of partners during the last three months, percent unprotected sex during the last 3 months, condom attitudes, condom use skills, prevention beliefs, or behavioral intentions [47]. Yet still, as with the other drugs of interest, cocaine use influences mesolimbic dopamine transmission [48], which some have suggested influences perception of individual gratification [49].

Even inclusive of the stated limitations, the findings herein support research which notes that maturational changes in brain contribute to the age-specific behavioral characteristics of adolescence such as an increased likelihood to use drugs like cocaine and other peer-directed social interactions and elevated risk-taking behaviors [50,51] such as sex without a condom [52]. This may be why some have suggested that such behavioral observations are consistent with maturational changes in brain observed from early to late adolescence specific to developmental brain chemistry [51]. Moreover, based on the aforementioned and since adolescence as a developmental period is marked by a greater probability to initiate drug use and with an increased risk to develop addiction and adulthood dependency [53], exploring cocaine use among adolescent with a history of problem behavior and interaction with the criminal justice system may enable the creation of more targeted interventions that focus on problem behavior, drug use and sexual risk taking [54]. 


\section{References}

1 Martins MC, Pillon SC (2008) [Relationship between first-time drug use and first offense among adolescents in conflict with the law]. Cad Saude Publica 24: 1112-1120.

2 Department of Health and Human Services US (2010) Healthy people 2010.

3 DiClemente RJ, Crosby RA (2003) Sexually transmitted diseases among adolescents: risk factors, antecedents, and prevention strategies. In: Adams GR, Berzonsky M (edr) Blackwell handbook of adolescence. Oxford: Blackwell Publishers Ltd, UK.

4 Suellentrop K, Morrow B, Williams L, D'Angelo D; Centers for Disease Control and Prevention (CDC) (2006) Monitoring progress toward achieving Maternal and Infant Healthy People 2010 objectives--19 states, Pregnancy Risk Assessment Monitoring System (PRAMS), 20002003. MMWR Surveill Summ 55: 1-11.

5 Weinstock H, Berman S, Cates W Jr (2004) Sexually transmitted diseases among American youth: incidence and prevalence estimates, 2000. Perspect Sex Reprod Health 36: 6-10.

6 Johnson BT, Carey MP, Marsh KL, Levin KD, Scott-Sheldon LA (2003) Interventions to reduce sexual risk for the human immunodeficiency virus in adolescents, 1985-2000: a research synthesis. Arch Pediatr Adolesc Med 157: 381-388.

7 Braithwaite R, Conerly R, Robillard, Stephens TT, Woodring T (2003) Alcohol And Other Drug Use Among Adolescent Detainees. Journal Of Substance Use 8: 126-131.

8 Gordon K, Edelman J, Justice A, et al (2013) Sexual risk behaviors among minority men who have sex with men with and without HIV. Antimicrobial Resistance and Infection Control 2: P315.

9 Lopez V, Kopak A, Robillard A, Gillmore MR, Holliday RC, et al. (2011) Pathways to sexual risk taking among female adolescent detainees. J Youth Adolesc 40: 945-957.

10 Stephens T, Braithwaite R, Conerly R (2006) A Profile of Self-Reported Injection Drug Use and Needle Sharing Behavior Among Soon-to-beReleased Adult Male Inmates. American Journal of Health Studies 20: 65-70.

11 Benjet C, Borges G, Medina-Mora M, Fleiz C, Blanco J, et al (2007) Prevalance and socio-demographic correlates of drug use among adolescents: results from the Mexican Adolescent Mental Health Survey. Addictions 102: 1261-1268.

12 Tolou-Shams M, Houck CD, Nugent N, Conrad SM, Reyes A, et al. (2012) Alcohol Use and HIV Risk among Juvenile Drug Court Offenders. J Soc Work Pract Addict 12: 178-188.

13 Johnson BT, Carey MP, Marsh KL, Levin KD, Scott-Sheldon LA (2003) Interventions to reduce sexual risk for the human immunodeficiency virus in adolescents, 1985-2000: a research synthesis. Arch Pediatr Adolesc Med 157: 381-388.

14 Pedlow CT, Carey MP (2004) Developmentally appropriate sexual risk reduction interventions for adolescents: rationale, review of interventions, and recommendations for research and practice. Ann Behav Med 27: 172-184.

15 Sales JM, Milhausen RR, Diclemente RJ (2006) A decade in review: building on the experiences of past adolescent STI/HIV interventions to optimise future prevention efforts. Sex Transm Infect 82: 431-436.

16 Mullen PD, Ramirez G, Strouse D, Hedges LV, Sogolow E, et al. (2002) Meta-analysis of the effects of behavioral HIV prevention interventions on the sexual behavior of sexually experienced adolescents in controlled studies in the United States. J Acquir Immune Defic Syndr 30: S94-S105.

17 Leigh BC, Ames SL, Stacy AW (2008) Alcohol, drugs, and condom use among drug offenders: an event-based analysis. Drug Alcohol Depend 93: 38-42.

18 Braithwaite R, Stephens T (2005) Use of protective barriers and unprotected sex among adult male prison inmates prior to incarceration. Int J STD AIDS 16: 224-226.

19 Henggeler SW, McCart MR, Cunningham PB, Chapman JE (2012) Enhancing the effectiveness of juvenile drug courts by integrating evidence-based practices. J Consult Clin Psychol 80: 264-275.

20 Lucenko BA, Malow RM, Sanchez-Martinez M, Jennings T, Dévieux JG (2003) Negative Affect and HIV Risk in Alcohol and Other Drug (AOD) Abusing Adolescent Offenders. J Child Adolesc Subst Abuse 13: $1-17$

21 Kingree JB, Braithwaite R, Woodring $T$ (2000) Unprotected sex as a function of alcohol and marijuana use among adolescent detainees. J Adolesc Health 27: 179-185.

22 Cohen DA, Farley TA, Taylor SN, Martin DH, Schuster MA (2002) When and where do youths have sex? The potential role of adult supervision. Pediatrics 110: e66.

23 Teplin LA, Mericle AA, McClelland GM, Abram KM (2003) HIV and AIDS risk behaviors in juvenile detainees: implications for public health policy. Am J Public Health 93: 906-912.

24 Robertson AA, Stein JA, Baird-Thomas C (2006) Gender differences in the prediction of condom use among incarcerated juvenile offenders: testing the information-motivation-behavior skills (IMB) model. Journal of Adolescent Health 38: 18-25.

25 Lucenko BA, Malow RM, Sanchez-Martinez M, Jennings T, Dévieux JG (2003) Negative Affect and HIV Risk in Alcohol and Other Drug (AOD) Abusing Adolescent Offenders. J Child Adolesc Subst Abuse 13: 1-17.

26 Tsay S, Childs G, Cook-Heard D, Sturdevant M (2013) Correlates of condom self-efficacy in an incarcerated juvenile population. J Correct Health Care 19: 27-35.

27 Richardson Jr JB, Brown J, Van Brakle M, Godette DC (2010) HIV Risk Behaviors Among African American Male Violent Youth Offenders. Journal of Offender Rehabilitation 49: 520-535.

28 Castrucci BC, Martin SL (2002) The association between substance use and risky sexual behaviors among incarcerated adolescents. Matern Child Health J 6: 43-47.

29 Tolou-Shams M, Ewing SW, Tarantino N, Brown LK (2010) Crack and Cocaine Use among Adolescents in Psychiatric Treatment: Associations with HIV Risk. J Child Adolesc Subst Abuse 19: 122-134.

30 Orr DP, Johnston K, Brizendine E, Katz B, Fortenberry JD (2001) Subsequent sexually transmitted infection in urban adolescents and young adults. Archives Pediatr Adolescent Medicine 155: 947953.

31 Childs K, Dembo R, Belenko S, Wareham J, Schmeidler J (2011) A Comparison of Individual-Level and Community-Level Predictors of Marijuana and Cocaine Use among a Sample of Newly Arrested Juvenile Offenders. Journal of Child and Adolescent Substance Abuse 20:114-134

32 Kim JY, Fendrich M (2002) Gender differences in juvenile arrestees' drug use, self-reported dependence, and perceived need for treatment. Psychiatr Serv 53: 70-75. 
33 Magura S, Shapiro JL, Kang SY (1994) Condom use among criminallyinvolved adolescents. AIDS Care 6: 595-603.

34 Caudill BD, Hoffman JA, Hubbard RL, Flynn PM, Luckey JW (1994) Parental history of substance abuse as a risk factor in predicting crack smokers' substance use, illegal activities, and psychiatric status. Am J Drug Alcohol Abuse 20: 341-354.

35 Zun LS, Downey L, Rosen J (2005) Who are the young victims of violence? Pediatr Emerg Care 21: 568-573.

36 Friedman AS, Terras A, Glassman K (2003) The differential disinhibition effect of marijuana use on violent behavior: a comparison of this effect on a conventional, non-delinquent group versus a delinquent or deviant group. J Addict Dis 22: 63-78.

37 Duncan RD, Kennedy WA, Smith DW (2000) Comparison of conductdisordered behavior in crack-dealing versus nondealing juvenile offenders. Psychol Rep 86: 1089-1096.

38 Kang SY, Magura S, Shapiro JL (1994) Correlates of cocaine/crack use among inner-city incarcerated adolescents. Am J Drug Alcohol Abuse 20: 413-429.

39 Stephens TT, Braithwaite RL, Turner J (2011) Determinants of Violent Problem Behavior among Adolescent Detainees in the US State of Georgia. International Journal of Prisoner Health 7: 53-60.

40 Shrier LA, Crosby R (2003) Correlates of sexual experience among a nationally representative sample of alternative high school students. J Sch Health 73: 197-200.

41 Begley E, Crosby RA, DiClemente RJ, Wingood GM, Rose E (2003) Older partners and STD prevalence among pregnant African American teens. Sex Transm Dis 30: 211-213.

42 Ochs EP, Binik YM (1999) The use of couple data to determine the reliability of self-reported sexual behavior. J Sex Res 36: 374-384.

43 Jaccard J, Wan CK (1995) A paradigm for studying the accuracy of self-reports of risk behavior relevant to AIDS: empirical perspectives on stability, recall bias, and transitory influences. J Appl Soc Psychol 25: 1831-1858.
44 Szumilas M (2010) Explaining odds ratios. J Can Acad Child Adolesc Psychiatry 19: 227-229.

45 Garner C (2007) Upward bias in odds ratio estimates from genomewide association studies. Genet Epidemiol 31: 288-295.

46 Nemes S, Jonasson JM, Genell A, Steineck G (2009) Bias in odds ratios by logistic regression modelling and sample size. BMC Med Res Methodol 9: 56.

47 Dévieux J, Malow R, Stein JA, Jennings TE, Lucenko BA, et al. (2002) Impulsivity and HIV Risk Among Adjudicated Alcohol- and Other Drug-Abusing Adolescent Offenders. AIDS Educ Prev 14: 24-35.

48 Hardin MG, Ernst M (2009) Functional brain imaging of developmentrelated risk and vulnerability for substance use in adolescents. J Addict Med 3: 47-54.

49 Ayduk O, Mendoza-Denton R, Mischel W, Downey G, Peake PK, et al. (2000) Regulating the interpersonal self: strategic self-regulation for coping with rejection sensitivity. J Pers Soc Psychol 79: 776-792.

50 Spear LP (2000) The adolescent brain and age-related behavioral manifestations. Neurosci Biobehav Rev 24: 417-463.

51 Stansfield $\mathrm{KH}$, Kirstein CL (2006) Effects of novelty on behavior in the adolescent and adult rat. Dev Psychobiol 48: 10-15.

52 Stephens TT (2015) Sex-Related Marijuana Expectancies of Social Desirability Among Detained Male and Female Adolescent Offenders in the USA. Journal of Behavioral Health 4: 101-106.

53 Badanich KA, Adler KJ, Kirstein CL (2006) Adolescents differ from adults in cocaine conditioned place preference and cocaine-induced dopamine in the nucleus accumbens septi. European Journal of Pharmacology 550: 95-106.

54 Stephens TT, Conerly Holliday R, Hopkins S, Rose S, Braithwaite R, et al. (2015) Correlates of African American Female Adolescent Offenders 3,4-Methylenedioxymethamphetamine (MDMA or 'Ecstasy') Use and Sexually Transmitted Infection (STI) Morbidity. Journal of Human Behavior in the Social Environment. 